Revista de

Contabilidade e

Organizações

www.rco.usp.br
DOI: http://dx.doi.org/10.11606/rco.v11i30.134529
Journal of

Accounting and

Organizations

www.rco.usp.br

\title{
Corrupção e ineficiência em licitações de governos locais e desenvolvimento humano: novas reflexões
}

Corruption and inefficiency in local governments 'procurement processes and human development: new reflections

Ícaro Saraiva Laurinho ; Lidiane Nazaré da Silva Dias ${ }^{\mathrm{a}}$; Carlos André Corrêa de Mattos ${ }^{\mathrm{a}}$;

${ }^{a}$ Universidade Federal do Pará

Palavras-chave

Corrupção.

Ineficiência.

Licitações.

Desenvolvimento humano.

Municípios.

Saúde pública.
Keywords

Corruption.

Inefficiency.

Public procurement.

Human development.

Local governments.

Public health.

\section{Informações do Artigo}

Recebido: 17 de julho de 2017

Aceito: 12 de setembro de 2017

\begin{abstract}
Resumo
Corrupção e ineficiência em contratações públicas e a associação com nível de desenvolvimento humano têm sido evidenciados em diversos países e governos. $\mathrm{O}$ presente artigo analisa a associação de irregularidades identificadas em licitações na função saúde em municípios brasileiros nos anos de 2010 a 2012. A presença de irregularidade está associada a um baixo desenvolvimento humano dos municípios considerados. A reflexão feita aqui é que, apesar de não ser possível pela metodologia afirmar causalidade entre corrupção e baixo desenvolvimento humano, há indícios de que a existência de tais práticas pode estar justamente associada ao baixo índice de desenvolvimento humano existente. Como implicação prática sugere-se o aumento da transparência dos processos e da atuação dos órgãos de controle, dado que o ambiente social local pode facilitar práticas clientelistas que criam oportunidades favoráveis à corrupção.
\end{abstract}

\begin{abstract}
Corruption and inefficiency in public contracting, and the association with human development level has been coming up in various countries and governments. This article analyzes an association of identified irregularities in biddings for health in Brazilian municipalities from 2010 to 2012 showing the same association. The presence of irregularities is mainly due to a low human development in the observed locations. The reflection done here shows that, although it is not possible through methodology to assure casualty between corruption and human development, it is believed that the existence of such practice may be related to the low HDI. As a practical implication, it is suggested the raising of public transparency and broader actuation for controlling institutions, since the social environment in the location might ease patronage practices, and advantages which are favorable opportunities for corruption.
\end{abstract}

Copyright (C) 2017 FEA-RP/USP. Todos os direitos reservados

\section{INTRODUÇÃO}

Trinta e oito bilhões de reais é o valor, incluindo multas, que o Ministério Público Federal (MPF) está pedindo em ressarcimentos relacionados aos processos da Operação Lava Jato, iniciada em março de 2014 (MPF, 2017). O esquema criminoso relacionado a desvios de recursos da Petrobras descoberto pela força-tarefa evidencia uma estreita relação entre processos licitatórios e corrupção. Foi comprovado que a operacionalização dos desvios de recursos ocorria com a organização de cartéis entre as grandes empreiteiras, que pagavam propinas entre $1 \%$ a $5 \%$ do montante dos contratos superfaturados para a execução de obras. Tais contratos foram obtidos por meio de processos licitatórios aparentemente lícitos (MPF, 2017).

$\mathrm{Na}$ contramão desse desperdício de recursos públicos por corrupção, inserida em uma crise políticaeconômica, a situação financeira do Brasil é crítica em 2017. O governo chegou ao ponto de sugerir uma redução no valor da proposta inicial do salário mínimo de 2018, em R $\$ 10$, o que levaria à economia de três bilhões de reais ${ }^{1}$.

${ }^{1}$ Fonte da informação: Governo propõe salário mínimo de R\$10 menor em 2018, de R\$969. G1 Economia. Disponível em:

Autor Correspondente: Tel. (91) 3201-8051

E-mail: icarolaurinho@gmail.com (I. S. Lauinho); lidianedias@ufpa.br (L. N. S. Dias); carlosacmattos@hotmail.com (C. A. C. Mattos)

Universidade Federal do Pará. Rua Augusto Corrêa, 1 - Guamá, Belém - PA, 66.075-110 
Mas isto seria um pequeno percentual quando comparado aos valores dos desvios identificados pela Lava-Jato. Esse é um exemplo, dentre outros tantos, de desperdício de recursos ocasionados pela corrupção, a qual é constantemente abordada como um dos principais problemas para a gestão pública. $\mathrm{O}$ desperdício de recursos públicos é conceituado por Bandiera, Prat e Valletti (2009) como todos os gastos desnecessários realizados pela administração pública, classificando-o em corrupção e ineficiência.

Corrupção e ineficiência são fenômenos associados, mas distintos. Por um lado, a corrupção é uma clara quebra de regras de convívio, administrativas e morais, gerando um prejuízo ao erário público, como contrapartida pela realização do ato ilícito (Jain, 2001; Tanzi,1998). Já a ineficiência relaciona-se à má utilização de recursos, o que gera gastos desnecessários, financeiros ou não, ao poder público (Bandiera et al., 2009).

Apesar da ineficiência não receber o mesmo destaque que a corrupção, alguns estudos mostram que ela pode ser até mais impactante. Por exemplo, na Itália a ineficiência chega a 83\% dos gastos desnecessários na aquisição de bens (Bandiera et al., 2009).

A corrupção está presente em diversos países, apesar de em distintos níveis. A corrupção em contratos com o governo, que envolve propinas a agentes públicos e captura de renda por agentes privados, também ocorre em países desenvolvidos (Hessami, 2014). Tem sido mostrado que existe uma relação inversa tanto com o desenvolvimento econômico (Treisman, 2000) quanto com o desenvolvimento humano (Akçay, 2006). Este resultado foi validado no Brasil, Ferraz, Finan e Moreira $(2008 ; 2012)$ mostram efeito da corrupção na educação, e Gupta, Davoodi e Tiongson (2000) e Dias (2016) mostram associação com políticas de saúde.

Em geral a literatura que trata de corrupção e desenvolvimento humano discute governos centrais e os impactos nacionais (ex. Abed e Davoodi, 2000; Mo, 2001; Benfratello, Del Monte e Pennacchio, 2017). Ainda, discutem a corrupção como causa de um baixo índice de desenvolvimento humano (IDH). Pouco se discute sobre governos locais, e eventualmente se IDH é mais um contexto para corrupção e não apenas um efeito. Este artigo faz uma reflexão dessa associação (corrupção e IDH) em governos locais brasileiros, adicionando-se a discussão a ineficiência da gestão pública, a qual tem se mostrado relevante no contexto (Bandeira et al, 2009). Para isto, foca especificamente em uma função de governo, no caso "saúde".

Como educação e saúde reúnem 10\% do PIB brasileiro, são áreas com maior montante de recursos públicos investidos no Brasil (Ferraz, Finan \& Moreira, 2008; 2012). Não se tem notícia, no nosso melhor entendimento, da existência de estudos empíricos entre o IDHM e a corrupção e ineficiência em processos licitatórios de saúde em governos locais brasileiros. O setor de saúde envolve recursos empregados nas compras governamentais como um todo, estimado entre 10 e 15\% do PIB brasileiro (Silva \& Barki, 2012), sendo um fator atrativo para a atividade rent seeking, como observado no estudo de Herrmann (1999). A obrigatoriedade de municípios brasileiros investirem pelo menos $15 \%$ de sua receita própria na saúde para o atendimento da Ementa Constitucional n ${ }^{\circ}$ 29/2000 garante um fluxo contínuo de recursos para os contratos associados, sendo uma constante fonte de ineficiência e potencial corrupção.

Corrupção e Ineficiência são alvo de análise do Programa de Fiscalização por Sorteios Públicos (PFSP) do Ministério da Transparência e Controladoria-Geral da União (CGU). O programa foi empregado de 2003 a 2015 e os resultados das auditorias indicam que os casos envolvendo corrupção e/ou ineficiência estão presentes na maioria dos municípios auditados. Nesta pesquisa os dados levantados no programa 'PFSP' são usados como proxies de corrupção e ineficiência em licitações na área da saúde. Destaca-se que mesmo sendo utilizados recorrentemente em pesquisas no tema no Brasil, os dados do PFSP - como proxy de corrupção e ineficiência - não focam exclusivamente as licitações (como o de Dias, Matias-Pereira, Farias \& Pamplona, 2013). Trabalhou-se com o corte temporal de 2010 a 2012 para testar a associação com o Índice de Desenvolvimento Humano Municipal IDHM (2010) de 281 municípios brasileiros.

O texto a seguir apresentará que é constante a ocorrência de casos de corrupção, mas principalmente de ineficiência nos procedimentos licitatórios do país relativos ao setor de saúde pública (o que provavelmente também ocorre em outros setores). Dessa forma, evidencia-se a urgência no aperfeiçoamento de controles institucionais e sociais e da transparência pública para o monitoramento da aplicação dos recursos empregados nas compras governamentais, o que repercutirá na qualidade de vida da população e no desenvolvimento humano municipal.

\footnotetext{
$<\mathrm{http} / /$ g1.globo.com/economia/noticia/governo-baixa-em-r-10-para-r-969-proposta-para-salario-minimo-em-2018-e-economiza-r-3-bilhoes.ghtml>.
} 


\section{LITERATURA EM CORRUPÇ̃̃O, INEFICIÊNCIA E DESENVOLVIMENTO HUMANO}

A corrupção não é um fenômeno exclusivo de países subdesenvolvidos e com recente contato com a democracia, ela vem se manifestando ao longo do tempo em várias sociedades (Treisman, 2000; Klitgaard, 1994). E a gestão pública nas áreas sociais (saúde, educação e assistência) é influenciada pela ocorrência tanto de tais práticas de corrupção quanto pela simples ineficiência, as quais, se eliminadas, provocam aumento de bem-estar econômico (Reinikka \& Svensson, 2005; Pereira \& Campos, 2016).

Autores como Ferraz e Finan (2007), Shleifer e Vishny (1993), Tanzi e Davoodi (1997) e Mauro (1995) afirmam que a corrupção retarda o crescimento econômico e distorce a alocação de recursos, direcionando os mesmos para áreas as quais os recursos possam ser mais facilmente capturados. Esse fato afeta a eficiência do Estado pois além da perda pelo desperdício ocorre também o remanejamento de valores para outras áreas independente da demanda real, privilegiando gastos atrelados a realização de despesas que exigem um volume maior de recursos em detrimento da real necessidade da população, afetando áreas que tem estreita relação com o desenvolvimento humano, como saúde e educação (Gupta, Davoodi \& Tiongson, 2000).

O conceito de desenvolvimento humano era visto unicamente ligado ao crescimento econômico, no entanto na década de 70 esta visão começou a mudar (Sant'Ana, 2008), fundamentada na hipótese de que a evolução de um país ou município não pode ser mensurada apenas pela renda de cada indivíduo, mas há de se considerar outros fatores relevantes, tais como: saúde, educação e qualidade dos serviços (Scarpin \& Slomski, 2007).

Uma das métricas mais utilizadas para captar o conceito de desenvolvimento humano é o Índice de Desenvolvimento Humano (IDH), que capta no longo prazo a evolução de três dimensões básicas: renda, educação e saúde. Destaca-se que o fato do IDH ser multidimensional permite analisar a prática das políticas sociais dos diferentes países (Sant'Ana, 2008). No nível local, o Índice de Desenvolvimento Humano Municipal (IDHM), é influenciado pela expectativa de vida ao nascer, por índices de escolaridade e pela renda média per capta, não podendo ser comparado com o IDH Global por diferenças metodológicas de construção (Atlas, 2017).

A literatura anterior já apresenta relações entre corrupção e crescimento econômico (Mauro, 1996; Leite \& Weideman, 1999; Mo, 2001; Tanzi \& Davoodi, 2000; e Abed \& Davoodi, 2000; Gupta, Davoodi, e AlonsoTerme, 1998). Partindo-se do fato de que o crescimento econômico, medido pelo PIB, é um dos fatores que compõem o IDH, é possível estabelecer uma relação entre ele e a corrupção.

Apesar dos estudos não abordarem a questão da causalidade na relação entre o desenvolvimento econômico e a corrupção, os fatores associados ao desenvolvimento humano são diretamente impactados pela corrupção (Mauro, 1998; Gupta et al, 2000; Kaufmann, Kraay \& Zoido-Lobatón, 1999). Contudo, não se sabe se é o crescimento econômico que influencia a corrupção ou o inverso, ponto esse que dificilmente será resolvido (Mauro, 1995).

A literatura tem evidenciado que os gestores não querem gastar mais em educação e saúde porque esses programas de gastos oferecem menos oportunidade para o rent seeking. Por essa lógica de rent seeking, organizações buscariam ganhos extraordinários não atrelados a suas atividades operacionais, que poderiam vir de práticas de corrupção. Os estudos seminais de Tullock (1967), Krueger (1974), Posner (1975) tratam que a ocorrência de rent seeking surge quando empresas alocam recursos para capturar a administração pública, criando barreiras artificiais que impedem a real concorrência. Naquele momento a atividade rent seeking transformaria os lucros monopolistas em custos sociais ao capturar a renda realizada com a obtenção dos privilégios e/ou dos monopólios (Tullock, 1967), o que pode ser observado no caso da Petrobras, citado anteriormente.

A Tabela 1 apresenta o resumo da literatura sobre o impacto da corrupção em diferentes países. 
Tabela 1. Resumo da Literatura sobre o impacto da corrupção

\begin{tabular}{|c|c|c|c|}
\hline Autor(es) & $\begin{array}{l}\text { Associação proposta } \\
\text { entre corrupção e: }\end{array}$ & Relação encontrada & Esfera governo \\
\hline Mauro (1996) & Crescimento real do PIB/capita & Negativa & $\begin{array}{l}\text { Governo central, } \\
103 \text { países. }\end{array}$ \\
\hline Leite e Weideman (1999) & Crescimento real do PIB/capita & Negativa & $\begin{array}{l}\text { Governo central, } \\
72 \text { países }\end{array}$ \\
\hline Abed e Davoodi (2000) & Crescimento real do PIB/capita & Negativa & $\begin{array}{l}\text { Governo central, } \\
25 \text { países }\end{array}$ \\
\hline Mo (2001) & Crescimento real do PIB/capita & Negativa & $\begin{array}{l}\text { Governo central, } \\
45 \text { países }\end{array}$ \\
\hline $\begin{array}{l}\text { Benfratello, Del Monte e } \\
\text { Pennacchio (2017) }\end{array}$ & $\begin{array}{l}\text { Dívida pública e crescimento real } \\
\text { do PIB/capita } \\
\text { (relativizado pela redução do } \\
\text { endividamento dos estados) }\end{array}$ & $\begin{array}{l}\text { Positiva entre corrupção e } \\
\text { dívida pública; e negativa } \\
\text { entre a corrupção e o } \\
\text { crescimento real do PIB/ } \\
\text { capta }\end{array}$ & $\begin{array}{l}\text { Governo central, } \\
166 \text { países }\end{array}$ \\
\hline Mauro (1996) & Investimento privado e PIB & Negativa & $\begin{array}{l}\text { Governo central, } \\
103 \text { países }\end{array}$ \\
\hline Tanzi e Davoodi (1997) & $\begin{array}{l}\text { Investimento público } \\
\text { (relativizada pelo PIB) }\end{array}$ & Positiva & $\begin{array}{l}\text { Governo central, } \\
42 \text { a } 95 \text { países }\end{array}$ \\
\hline Tanzi e Davoodi (1997) & Receitas governamentais & Negativa & $\begin{array}{l}\text { Governo central, } \\
42 \text { a } 95 \text { países }\end{array}$ \\
\hline Tanzi e Davoodi (1997) & $\begin{array}{c}\text { Percentual de estradas } \\
\text { pavimentadas em boa condição }\end{array}$ & Negativa & $\begin{array}{l}\text { Governo central, } \\
42 \text { a } 95 \text { países }\end{array}$ \\
\hline Mauro (1998) & $\begin{array}{c}\text { Relação entre gastos em educação } \\
\text { pública e PIB }\end{array}$ & Negativa & $\begin{array}{l}\text { Governo central, } \\
103 \text { países }\end{array}$ \\
\hline $\begin{array}{l}\text { Gupta, Davoodi e } \\
\text { Tiongson (2000) }\end{array}$ & $\begin{array}{c}\text { Taxa de abandono escolar } \\
\text { primário }\end{array}$ & Positiva & $\begin{array}{l}\text { Governo central, } \\
117 \text { países }\end{array}$ \\
\hline Mauro (1998) & $\begin{array}{l}\text { Relação entre gastos em saúde } \\
\text { pública e PIB }\end{array}$ & Negativa & $\begin{array}{l}\text { Governo central, } \\
103 \text { países }\end{array}$ \\
\hline $\begin{array}{l}\text { Gupta, de Mello e Sharan } \\
\text { (2001) }\end{array}$ & $\begin{array}{c}\text { Gastos militares } \\
\text { (relativizada pelo PIB) }\end{array}$ & Positiva & $\begin{array}{l}\text { Governo central, } \\
120 \text { países }\end{array}$ \\
\hline Ghura (1998) & Receita do fiscal e PIB & Negativa & $\begin{array}{l}\text { Governo central, } \\
39 \text { países }\end{array}$ \\
\hline Tanzi e Davoodi (2000) & $\begin{array}{l}\text { Receita do governo* } \\
\text { (relativizada pelo PIB) }\end{array}$ & Negativa & $\begin{array}{l}\text { Governo central, } \\
90 \text { países }\end{array}$ \\
\hline $\begin{array}{l}\text { Gupta, Davoodi, e } \\
\text { Alonso-Terme (1998) }\end{array}$ & $\begin{array}{l}\text { Desigualdade de renda e } \\
\text { crescimento da renda dos pobres } \\
\text { (coeficiente de Gini) }\end{array}$ & $\begin{array}{l}\text { Relação positiva com } \\
\text { a desigualdade de } \\
\text { renda; e negativa com o } \\
\text { crescimento da renda dos } \\
\text { pobres }\end{array}$ & $\begin{array}{l}\text { Governo central, } \\
38 \text { a } 87 \text { países }\end{array}$ \\
\hline $\begin{array}{l}\text { Gupta, Davoodi e } \\
\text { Tiongson (2000) }\end{array}$ & Indicadores de saúde e educação & Negativa & $\begin{array}{l}\text { Governo central, } \\
81 \text { a } 117 \text { países }\end{array}$ \\
\hline Akçay (2006) & Desenvolvimento humano & Negativa & $\begin{array}{l}\text { Governo central, } \\
63 \text { países }\end{array}$ \\
\hline $\begin{array}{l}\text { Ferraz, Finan e Moreira } \\
(2008 ; 2012)\end{array}$ & $\begin{array}{l}\text { Desempenho dos alunos no } \\
\text { ensino primário }\end{array}$ & Negativa & $\begin{array}{c}\text { Governos locais, } 365 \\
\text { municípios, Brasil }\end{array}$ \\
\hline
\end{tabular}

Fonte: Transparência Internacional (2001 p. 256) e revisão da literatura.

Nota. As pesquisas aqui apresentadas realizadas em governo central referem-se a estudos cross-country. *Obtida através da receita tributária (imposto sobre renda, impostos sobre ganhos de capital e lucros, imposto sobre seguridade social, imposto sobre os salários), impostos nacionais sobre bens e serviços, impostos comerciais (importação e exportação) e receita não tributária. 


\section{METODOLOGIA}

Para testar a associação entre corrupção, ineficiência e desenvolvimento humano, o estudo utilizou os relatórios do PFSP para a construção de proxies de corrupção e ineficiência. E para a proxy de desenvolvimento humano utilizou-se o IDHM. O IDHM emprega em seus cálculos a média geométrica das dimensões: vida longa e saudável (saúde); acesso ao conhecimento (educação); e padrão de vida (renda). Essas dimensões têm como respectivos indicadores, a esperança de vida ao nascer, a escolaridade da população adulta, o fluxo escolar da população jovem e a renda mensal per capita.

As constatações identificadas referentes aos processos licitatórios do setor da saúde presentes nos relatórios foram classificadas conforme Tabela 2.

Tabela 2. Classificação de corrupção e ineficiência nas licitações da saúde

\begin{tabular}{lcc}
\hline TIPOS DESCRIÇÃO (como pode ser caracterizada a ocorrência) \\
\hline DESPERDÍCIOS POR CORRUPÇÃO
\end{tabular}

Desvios em licitações

Superfaturamento

Montagem, conluio e simulação de licitação

Direcionamento de licitação

Participação de empresas inexistentes

Contratos e outros documentos falsificados

Licitação com 'laranjas'
Existe evidência que o serviço/produto licitado e pago não foi prestado/entregue.

São utilizados preços acima dos de mercado; ou não é utilizada a proposta mais vantajosa economicamente; ou não são obedecidos os preços já acordados ou os preços estão em desacordo com tabela do SUS.

Empresas ou servidores e empresas se unem com o objetivo de fraudar o processo licitatório.

Há o favorecimento de alguma empresa.

O processo licitatório obtém participação de empresas inexistentes (exemplo: empresas de fachada ou fantasmas).

O processo licitatório obtém contratos e outros documentos falsificados.

O prefeito, na licitação, usa parentes ou terceiros em benefício próprio.

\section{DESPERDÍCIOS POR INEFICIÊNCIA}

Licitação irregular

Outros problemas na licitação

Não realização de licitação

Irregularidades licitatórias relacionadas a obras

Licitação com falta de concorrência ou restrição ao caráter competitivo

Ausência de divulgação

Licitação fracionamento

Tipo inadequado de licitação
Foram identificadas irregularidades, impropriedades, falhas ou constatações de erros em documentações.

Qualquer outra irregularidade identificada no processo licitatório que não se encaixe nas variáveis acima.

A licitação deveria ter sido realizada, mas não o foi.

A obra foi entregue inacabada ou fora das especificações/condições contratuais.

O caráter competitivo do processo é violado.

Não há observância ao princípio da publicidade.

Despesas são fracionadas objetivando fuga de licitação ou alteração da modalidade licitatória.

Não é utilizada a modalidade adequada de licitação.

Fonte: Adaptado de CEPESP-FGV apud Lopes (2011, p. 106) e Ferraz et al. (2008, p. 13). 
Os relatórios do PFSP apontam constatações que representam problemas identificados na aplicação de recursos ou na execução de programas de governo financiados pela União e executados pelos municípios. No PFSP os municípios a serem auditados eram selecionados por sorteio (sistema igual ao da loteria da Caixa Econômica Federal), do qual participavam os que possuíam até 500 mil habitantes (excluídas as capitais), perfazendo um total de 5.521 municípios aptos a receberem a auditoria, representando 99,2\% dos municípios brasileiros (CGU, 2016). As auditorias ocorriam por meio de visita in loco, com a realização de inspeções de contas, documentos, vistoria física das obras e serviços, além de contato direto com a população local (CGU, 2016).

A unidade de análise refere-se às auditorias realizadas no período de 2010 a 2012, as quais representam um mandato do poder executivo municipal concluído, menos as auditorias ocorridas em 2009 por se referirem ao primeiro ano de mandato dos novos gestores. Esse corte se deve ao fato que as constatações identificadas nessas auditorias são, via de regra, atribuídas ao gestor anterior. Portanto não pertencem ao mandato selecionado para análise.

Das 324 auditorias realizadas no período, foram excluídas 21 pois aqueles governos neste ano não receberam repasses do governo central para saúde e 22 por não apontarem qualquer irregularidade em processos licitatórios. A amostra final inclui 281 auditorias realizadas com pelo menos um problema em licitação na área de saúde, somando R\$ 631 milhões em valores auditados (informação levantada nos relatórios analisados) em municípios de todos estados da federação. Os casos estão ilustrados na Tabela 3.

Tabela 3. Descrição da amostra

\begin{tabular}{lcccc}
\hline \multicolumn{1}{c}{ Região } & $\begin{array}{c}\text { Total de } \\
\text { auditorias } \\
\text { realizadas } \\
\text { no período } \\
\mathbf{2 0 1 0 - 2 0 1 2}\end{array}$ & $\begin{array}{c}\text { Amostra inicial } \\
\text { (municípios } \\
\text { auditados com } \\
\text { repasses para } \\
\text { área da saúde) }\end{array}$ & $\begin{array}{c}\text { Amostra final } \\
\text { (municípios com pelo } \\
\text { menos um problema } \\
\text { em licitaçã } \\
\text { da) na área }\end{array}$ & $\begin{array}{c}\text { \% de municípios auditados } \\
\text { que receberam repasses para o } \\
\text { setor de saúde e apresentaram } \\
\text { pelo menos um problema nos } \\
\text { processos licitatórios deste setor }\end{array}$ \\
\hline Norte & 39 & 36 & 36 & $100,00 \%$ \\
Nordeste & 131 & 124 & 118 & $90,08 \%$ \\
Sudeste & 76 & 69 & 61 & $80,26 \%$ \\
Centro-oeste & 27 & 26 & 24 & $88,89 \%$ \\
Sul & 51 & 48 & 42 & $82,35 \%$ \\
\hline Total & $\mathbf{3 2 4}$ & $\mathbf{3 0 3}$ & $\mathbf{2 8 1}$ & $\mathbf{8 6 , 7 3 \%}$ \\
\hline
\end{tabular}

Nota: (1) Inclui casos de corrupção e ineficiência, identificados segundo auditorias do Programa de Fiscalização por Sorteios Públicos (PFSP) do Ministério da Transparência e Controladoria-Geral da União (CGU).

Destaca-se que os municípios sorteados para serem auditados podem ser novamente sorteados no próximo ciclo (sorteio com reposição). No entanto, para a amostra final do estudo, as 281 auditorias representaram 281 municípios pois os mesmos não se repetem no período de análise, correspondendo a 165 municípios auditados em 2010, 97 em 2011 e 19 em 2012.

A Tabela 4 apresenta o resultado da estatística descritiva relativa a cada um dos tipos de desperdícios por corrupção e ineficiência, totalizando 1.655 ocorrências relativas a algum tipo de problema nos processos licitatórios da saúde, dos quais $23,93 \%$ correspondem a constatações de evidências de corrupção e 76,07\% de evidências de ineficiência o que ratifica Bandiera et al (2009), Ferraz et al. (2008) e Dias et al. (2013) que destacam em suas pesquisas a importância de se atentar para a ineficiência dado que ela ocorre em maior frequência que a corrupção, o que acarreta prejuízo ao erário público. 
Tabela 4. Estatística descritiva das constatações de desperdício (2010-2012)

\begin{tabular}{|c|c|c|c|c|c|c|}
\hline Tipos & Média & Máx. & $\begin{array}{l}\text { Desvio- } \\
\text { Padrão }\end{array}$ & $\begin{array}{l}\text { núm. de } \\
\text { ocorrências }\end{array}$ & $\begin{array}{c}\text { \% de } \\
\text { ocorrência } \\
\text { por tipo de } \\
\text { desperdício }\end{array}$ & $\begin{array}{c}\text { \% de } \\
\text { ocorrência } \\
\text { dentre o } \\
\text { total de } \\
\text { desperdício }\end{array}$ \\
\hline Desvios em licitações & 1,66 & 5 & 0,91 & 141 & $35,61 \%$ & $8,52 \%$ \\
\hline Superfaturamento & 1,59 & 13 & 1,10 & 140 & $35,35 \%$ & $8,46 \%$ \\
\hline $\begin{array}{l}\text { Montagem, conluio e simulação de } \\
\text { licitação }\end{array}$ & 2,02 & 11 & 0,98 & 85 & $21,46 \%$ & $5,14 \%$ \\
\hline Direcionamento de licitação & 1,4 & 4 & 0,37 & 21 & $5,30 \%$ & $1,27 \%$ \\
\hline $\begin{array}{l}\text { Participação de empresas } \\
\text { inexistentes }\end{array}$ & 1,33 & 2 & 0,15 & 4 & $1,01 \%$ & $0,24 \%$ \\
\hline $\begin{array}{l}\text { Contratos e outros documentos } \\
\text { falsificados }\end{array}$ & 1 & 1 & 0,10 & 3 & $0,76 \%$ & $0,18 \%$ \\
\hline Licitação com 'laranjas' & 2 & 2 & 0 & 2 & $0,51 \%$ & $0,12 \%$ \\
\hline $\begin{array}{l}\text { Desperdício por corrupção - } \\
\text { Total }\end{array}$ & 1,41 & 15 & 2,10 & 396 & $100 \%$ & $23,93 \%$ \\
\hline Licitação irregular & 2,46 & 11 & 2,00 & 408 & $32,41 \%$ & $24,65 \%$ \\
\hline Outros problemas na licitação & 2,57 & 10 & 1,90 & 355 & $28,20 \%$ & $21,45 \%$ \\
\hline Não realização de licitação & 1,44 & 5 & 0,86 & 167 & $13,26 \%$ & $10,09 \%$ \\
\hline $\begin{array}{l}\text { Irregularidades licitatórias } \\
\text { relacionadas a obras }\end{array}$ & 1,79 & 6 & 1,95 & 129 & $10,25 \%$ & $7,79 \%$ \\
\hline $\begin{array}{l}\text { Licitação com falta de } \\
\text { concorrência ou restrição ao } \\
\text { caráter competitivo }\end{array}$ & 1,45 & 5 & 0,70 & 80 & $6,35 \%$ & $4,83 \%$ \\
\hline Ausência de divulgação & 1,47 & 5 & 0,59 & 53 & $4,21 \%$ & $3,20 \%$ \\
\hline Licitação fracionamento & 1,2 & 3 & 0,40 & 36 & $2,86 \%$ & $2,18 \%$ \\
\hline Tipo inadequado de licitação & 1,48 & 5 & 0,46 & 31 & $2,46 \%$ & $1,87 \%$ \\
\hline $\begin{array}{l}\text { Desperdício por ineficiência - } \\
\text { Total }\end{array}$ & 4,48 & 26 & 4,42 & 1.259 & $100 \%$ & $76,07 \%$ \\
\hline
\end{tabular}

Fonte: Elaborado pelos autores.

Dentre as constatações relativas à corrupção evidenciada nos processos licitatórios do setor da saúde, os tipos "superfaturamento" e "desvios em licitações" foram as que ocorreram com maior frequência (aproximadamente 140 vezes cada uma). Juntas elas totalizaram pouco mais de $70 \%$ das ocorrências referente desperdício por corrupção em licitações na saúde.

Quanto à ineficiência nos processos licitatórios da saúde, o tipo "licitação irregular" foi a que mais se repetiu, representando $24,65 \%$ do total dos desperdícios por corrupção e ineficiência identificados, seguida da variável "outros problemas na licitação", com $21,45 \%$, relacionada a outras categorias não especificadas, evidenciando quão diversificada são as constatações de ineficiências nos processos licitatórios. Os dois tipos citados, quando analisados apenas no âmbito da ineficiência, representam $60,61 \%$ dessas constatações.

Um ponto a ser destacado, o qual pode ser um motivador para a ocorrência da ineficiência no processo licitatório relacionada à "licitação fracionamento", remete à falta de atualização dos limites de valores estabelecidos nas modalidades da Lei de Licitações, datada de 1993, e que não são ajustados desde maio de 1998. Nesse período o Índice de Preços ao Consumidor Amplo (IPCA) variou em 230,16\%, o que motivou um movimento no estado do Mato Grosso no sentido de atualizar, por decreto, os limites estabelecidos na Lei ${ }^{\circ}$ 8.666/93, com base no Índice IGP-M/FGV, movimento esse com o aval do Tribunal de Contas do Estado do Mato Grosso (TCE-MT) e, posteriormente, do Ministério Público do Estado, e que foi utilizado como parte da fundamentação de uma Nota Técnica da CGU ao Poder Executivo Federal apresentando proposta de alteração dos limites das modalidades de licitação previstas na Lei no 8.666/93 (TCE-MT, 2017). 
Para investigar a associação do desperdício de recursos da saúde pública municipal presente nos processos licitatórios, nas formas de corrupção e ineficiência, e sua relação com o desenvolvimento humano, foi utilizada a técnica multivariada de Regressão Linear Múltipla.

A Tabela 5 evidencia as variáveis presentes no modelo, bem como suas descrições, base teórica, fonte e sinal esperado.

Tabela 5. Variáveis utilizadas no estudo

\begin{tabular}{|c|c|c|c|c|}
\hline Base teórica & Variável & Descrição & Fonte & $\begin{array}{c}\text { Sinal } \\
\text { Esperado }\end{array}$ \\
\hline \multicolumn{5}{|l|}{ Variável Dependente } \\
\hline $\begin{array}{l}\text { Akçay (2006), Ferraz et } \\
\text { al. (2008; 2012), Mauro } \\
\text { (1998), Gupta, Davoodi e } \\
\text { Tiongson (2000) }\end{array}$ & IDHM & $\begin{array}{l}\text { Índice que varia de } 0 \text { e } 1 \text {; quanto mais } \\
\text { próximo de } 1 \text { maior é o desenvolvimento } \\
\text { humano do município }^{(1)}\end{array}$ & IBGE & \\
\hline \multicolumn{5}{|l|}{ Variáveis Independentes } \\
\hline \multirow{2}{*}{$\begin{array}{l}\text { Akçay (2006), Ferraz et } \\
\text { al. (2008; 2012); Mauro } \\
\text { (1998), Gupta, Davoodi e } \\
\text { Tiongson (2000), Tullock } \\
\text { (1967), Svensson (2005) }\end{array}$} & $\begin{array}{l}\text { Índice de } \\
\text { Corrupção }\end{array}$ & $\begin{array}{l}\text { Índice calculado pela divisão do número de } \\
\text { constatações classificadas como corrupção } \\
\text { pelo número de Ordens de Serviços, } \\
\text { parametrizados numa escala de } 0 \text { (melhor) a } 1 \\
\text { (pior) }^{(2)}\end{array}$ & $\begin{array}{l}\text { CGU e } \\
\text { Autores }\end{array}$ & Negativo \\
\hline & $\begin{array}{l}\text { Índice de } \\
\text { Ineficiência }\end{array}$ & $\begin{array}{l}\text { Indicador calculado pela divisão do número de } \\
\text { constatações classificadas como ineficiência } \\
\text { pelo número de Ordens de Serviços, } \\
\text { parametrizados numa escala de } 0 \text { (melhor) a } 1 \\
\text { (pior) }^{(2)}\end{array}$ & $\begin{array}{l}\text { CGU e } \\
\text { Autores }\end{array}$ & Negativo \\
\hline \multicolumn{5}{|l|}{ Variáveis de Controle } \\
\hline $\begin{array}{l}\text { Mauro (1998), Gupta, } \\
\text { Davoodi, e Alonso-Terme } \\
\text { (1998) }\end{array}$ & $\begin{array}{l}\text { Despesas na } \\
\text { função saúde/ } \\
\text { Transferências } \\
\text { da União (\%) }\end{array}$ & $\begin{array}{l}\text { Percentual de recursos transferidos da } \\
\text { União ao município para a área da saúde em } \\
\text { relação ao total de transferências da União ao } \\
\text { município no período auditado pela CGU.(3) }\end{array}$ & CGU & Positivo \\
\hline $\begin{array}{l}\text { Mauro (1998), Gupta et al. } \\
\text { (1998) }\end{array}$ & $\begin{array}{l}\text { Despesas na } \\
\text { função saúde/ } \\
\text { Receita Própria } \\
\text { (\%) }\end{array}$ & $\begin{array}{l}\text { Percentual de receita própria municipal } \\
\text { investida em saúde em atenção ao atendimento } \\
\text { da Emenda Constitucional nº29/2000 (mínimo } \\
\text { de } 15 \%) .{ }^{(4)}\end{array}$ & SIOPS & Positivo \\
\hline $\begin{array}{l}\text { Jain }(2001) ; \mathrm{Wu}(2005) \text {; } \\
\text { Mauro (1996) } \\
\text { Abed e Davoodi (2000) }\end{array}$ & $\mathrm{PIB} /$ capta & PIB per capta ${ }^{(1)}$ & IBGE & Positivo \\
\hline $\begin{array}{l}\text { Gupta, Davoodi, e Alonso- } \\
\text { Terme (1998) }\end{array}$ & $\begin{array}{l}\text { Igualdade de } \\
\text { renda }\end{array}$ & $\begin{array}{l}\text { Indicador calculado pelo inverso do Gini (1- } \\
\text { Gini), variando numa escala de } 0 \text { (pior) a } 1 \\
\text { (melhor) }^{(1)}\end{array}$ & IBGE & Positivo \\
\hline $\begin{array}{l}\text { Akçay (2006); Ferraz } \\
\text { e Finan (2008), Ferraz, } \\
\text { Finan e Moreira (2008; } \\
\text { 2012) }\end{array}$ & $\begin{array}{c}\text { Taxa de } \\
\text { Urbanização }\end{array}$ & $\begin{array}{l}\text { Percentual de população urbana do } \\
\text { município }^{(1)}\end{array}$ & IPEA & Positivo \\
\hline $\begin{array}{l}\text { Akçay (2006), Ferraz } \\
\text { e Finan (2008); Ferraz, } \\
\text { Finan e Moreria (2012) }\end{array}$ & População & População do município em logaritmo ${ }^{(1)}$ & IBGE & Positivo \\
\hline
\end{tabular}


A Tabela 6 apresenta a estatística descritiva das variáveis utilizadas no modelo. Verifica-se que na média, o setor de saúde pública é responsável por $25,7 \%$ das transferências de recursos vindas da União, e o valor médio investido na área com recursos próprios corresponde a 19,5\%, o que justifica a materialidade do estudo da área. No que concerne a renda, a amostra contempla municípios cujo PIB per capta varia entre R $\$ 2,2$ a $\mathrm{R} \$ 79,6$ mil, e população média de 17 mil habitantes, e urbanização média de 61,2\%.

Tabela 6. Estatística descritiva das variáveis do modelo

\begin{tabular}{rrrrcc}
\hline \multicolumn{1}{c}{ Variável } & Média & Mínimo & Máximo & $\begin{array}{c}\text { Devio- } \\
\text { Padrão }\end{array}$ \\
\hline & IDHM (2010) & 0,639 & 0,453 & 0,790 & 0,071 \\
& Índice de Corrupção & 0,135 & 0,000 & 1,000 & 0,175 \\
Índice de Ineficiência & 0,176 & 0,000 & 1,000 & 0,155 \\
Despesas na função saúde/Transferências da União (\%) & 0,257 & 0,006 & 0,883 & 0,166 & 0,045 \\
Despesas na função saúde/Receita Própria (\%) & 0,195 & 0,000 & 0,364 & 79.600 & 8.154 \\
PIB/capta & 9.980 & 2.272 & 0,66 & 0,068 \\
Igualdade de renda & 0,499 & 0,22 & 1,000 & 0,201 \\
Taxa de urbanização & 0,612 & 0,091 & 1,6 & 174,5 & 20,9 \\
\hline
\end{tabular}

Fonte: Elaborado pelos autores.

\section{RESULTADOS E DISCUSSÃO}

No que tange as limitações da pesquisa, é importante destacar que a teoria sugere uma relação de causalidade entre desenvolvimento humano (efeito) e desperdício de recursos corrupção e ineficiência (causa), o que poderia ser estudado empiricamente com a utilização de equações simultâneas. Para isso seria necessário que houvesse uma série temporal para as proxies de corrupção e ineficiência, além do próprio IDHM, o que não é possível pois: i) para a construção dos índices de corrupção e ineficiência utilizou-se como base os relatórios do PFSP, os quais não permitem a construção de uma série temporal; ii) o IDHM é calculado a cada 10 anos; e iii) o estudo de causalidade não é comum de dados cross-section pois nesse caso seria necessário que houvesse a variável tempo.

Desse modo, assim como Akçay (2006), os testes foram realizados considerando a associação entre as variáveis, e para minimizar esse problema, utilizou-se, como variável do controle o PIB per capta e, como no estudo de Akçay (2006), a taxa de urbanização. Destaca-se também que a amostra refere-se a um período anterior a Operação Lava-Jato, a qual sinaliza para um novo cenário onde passa a haver a percepção de aumento da fiscalização e eventual redução da impunidade.

Os resultados do modelo de regressão podem ser observados na Tabela 7. 
Tabela 7. Efeito no Índice de Desenvolvimento nos municípios, na corrupção e na ineficiência

\begin{tabular}{|c|c|c|c|}
\hline \multirow[t]{2}{*}{ Variável } & \multicolumn{3}{|c|}{$\begin{array}{c}\text { Coeficientes e } p \text {-valor } \\
\text { (corrigidos pela matriz de White) }\end{array}$} \\
\hline & Modelo 1 & Modelo 2 & Modelo 3 \\
\hline Variável dependente & IDHM & Corrupção & Ineficiência \\
\hline IDHM & - & $-0,48453 * *$ & $-0,79124 * * *$ \\
\hline Índice de Corrupção & $-0,03050 * *$ & - & $0,13695 * *$ \\
\hline Índice de Ineficiência & $-0,06788 * * *$ & $0,18662 * *$ & - \\
\hline Despesas na função saúde/Transferências da União (\%) & $0,09817 * * *$ & 0,01007 & $0,14098 * *$ \\
\hline Despesas na função saúde/Receita Própria (\%) & $0,11092 * *$ & $-0,40005^{* *}$ & 0,07849 \\
\hline PIB per capta $(\mathrm{R} \$ /$ hab $)$ & $0,00000 * * *$ & 0,00000 & $0,00000 * * *$ \\
\hline Igualdade de renda & $0,18951 * * *$ & 0,07720 & $-0,28650$ \\
\hline Taxa de urbanização (pop. urbana \%) & $0,11072 * * *$ & $-0,07130$ & 0,02527 \\
\hline Logaritmo da População & $-0,00498^{*}$ & 0,00959 & $-0,00632$ \\
\hline Const & $0,45928 * * *$ & $0,38759 * *$ & $0,73416^{* * *}$ \\
\hline $\mathrm{n}$ & 281 & 281 & 281 \\
\hline FIV & 1,243 & 1,594 & 1,551 \\
\hline P-valor $(F)$ & $0,000 * * *$ & $0,000 * * *$ & $0,001 * * *$ \\
\hline $\mathrm{R} 2$ & 0,661 & 0,107 & 0,166 \\
\hline
\end{tabular}

Fonte: Elaborado pelos autores.

Notas. Foram rodados três modelos com diferentes variáveis dependentes, IDHM no modelo 1, índice de corrupção no modelo 2; e índice de ineficiência no modelo 3. Para os três modelos as outras variáveis do estudo foram consideradas como variáveis independentes, permanecendo as mesmas variáveis de controle. Testou-se também um quarto modelo igual ao modelo 1 só que com a inclusão da variável "igualdade de renda $\mathrm{x}$ PIB per capta" como variável de controle a qual objetivava evidenciar a real distribuição do PIB, o qual pode ser distorcido com a concentração de renda; no entanto o VIF do modelo foi de 23,51, apresentando uma forte correlação no PIB per capta, por isso o mesmo não foi considerado no estudo. Quanto ao entendimento da tabela, os valores numéricos na primeira parte da tabela representam os coeficientes e os asteriscos o $p$-valor. A validação dos pressupostos adotados pelos modelos de regressão foi feita através da aplicação de testes quanto à independência dos resíduos, homocedasticidade, normalidade dos resíduos e ausência de multicolinearidade. A Estatística F apresentou significativa a 1\% para os 3 modelos, ou seja, globalmente as regressões são significativas e representativas. O teste de heterocedasticidade mostrou-se significativo, ou seja, os 3 modelos apresentam problema de heterocedasticidade, porém a mesma foi corrigida rodando os modelos com a correção da matriz robusta de White. As variáveis independentes utilizadas nos modelos não apresentam alta correlação entre si, o que elimina o problema da multicolinearidade, o que foi confirmado com o teste de Fator de Inflação da Variância.

* Significativo a $10 \% * *$, Significativo a $5 \%, * * *$ Significativo a $1 \%$.

Os 3 modelos apresentados na Tabela 7 evidenciam a relação esperada entre IDHM, corrupção e ineficiência. O IDHM, como era de se esperar, é em grande parte decorrente das próprias condições anteriores do município. Em Akçay (2006, p.34) a corrupção poderia ter um efeito "imediato" na redução do IDH, porém o IDH presente no município também decorre de um histórico de execução de políticas públicas, nível e eficiência dos investimentos feitos ao longo das gestões anteriores. Assim, a exemplo de Akçay (2006) que controlou o contexto prévio de 63 países em sua análise, foi controlado no presente modelo o PIB per capita e a taxa de urbanização de cada município. Utilizou-se também como variável de controle o logaritmo da população (visando captar o porte do município, o que não era feito por outras variáveis do modelo) e a igualdade da renda (para verificar a existência de ambiente propício ao clientelismo).

A relação população e IDH não é algo nada óbvio. No Brasil, alguns municípios populosos possuem um menor desenvolvimento social. Já o resultado da relação entre igualdade de renda e IDH evidenciou o esperado, uma renda melhor distribuída reflete numa população com mais recursos para o acesso a serviços (educação, saúde etc), o que influencia no IDH. Uma população melhor instruída possui maior nível de entendimento político-social capaz de cobrar dos governantes ações que levem ao desenvolvimento da comunidade e melhoria da qualidade de vida, sendo menos propícia a atuações clientelistas. 
O menor IDHM como era de se esperar também está associado à uma maior desigualdade de renda. Controlados tais efeitos, os resultados confirmam estudos anteriores, mostrando que a existência de corrupção e ineficiência tem associação com um menor IDHM. Isso pode decorrer de dois efeitos: (i) estes casos acontecem em municípios com menor desenvolvimento econômico e social, decorrente de uma maior presença de possíveis práticas clientelistas, ou (ii) na abordagem de análise mais tradicional, tanto corrupção como ineficiência com o passar do tempo reduzem o próprio IDHM, pelo maior desperdício de recursos.

Ao controlar por taxa de urbanização e PIB per capita isolou-se o efeito do nível de desenvolvimento local gerado ao longo dos últimos anos. Ao inserir taxa de urbanização e PIB per capita controla-se as condições de partida que o município tem, sejam decorrentes do histórico de eficiência ou ineficiência de investimentos e políticas públicas, seja devido a fatores históricos, sociais e econômicos. A lógica é, para municípios de urbanização e renda familiar (captada pelo PIB per capta) similares, o maior ou o menor IDHM atual estariam associados (por uma das duas direções causais apresentadas i ou ii) com as ineficiências ou práticas de corrupção no presente ou passado próximo.

Os resultados na Tabela 7 ratificam estudos anteriores. Ratificam Gupta et al. (2000), Ferraz et al. (2008; 2012) nas dimensões do desenvolvimento humano. E confirmam para governos locais no Brasil, o que Akçay (2006) mostrou para governos centrais em 63 países. Destaca-se que neste caso, foram analisados contratos especificamente da função saúde. Assim, como IDHM envolve outras dimensões além de saúde, não se pode afirmar que má aplicação de recursos em saúde é a única causa de um baixo IDHM local.

Entre os municípios que apresentaram irregularidades, um maior percentual de recursos investidos no setor de saúde no município, sejam eles advindos de transferência da União ou de aplicações de receitas próprias, está associado a um maior IDHM. Tal recurso não é significativamente capturado por atividade rent seeking, como o que se esperaria no contexto geral de presença de irregularidades. Mauro (1998) já havia identificado que gastos com saúde geram esse comportamento, diferente do apresentado na lógica de rent seeking, que em geral não trata do quanto seria capturado com o quanto geraria valor social. Isso sinaliza para alguma efetividade dos recursos orçamentários aplicados na saúde pública, refletidos em um maior IDHM, mesmo na presença de irregularidades.

Dito isto, aqui sugere-se uma interpretação alternativa àquela em geral tratada na literatura. Enquanto a literatura normalmente considera IDH como variável dependente, uma outra forma de analisar IDH é como contexto local. Sugere-se que o baixo IDHM é um ambiente propício às práticas de corrupção e ineficiência.

Este resultado é observado nos modelos 2 e 3, o aumento da corrupção associado ao aumento da ineficiência, ambas influenciadas por um baixo IDHM. Ou seja, um baixo IDHM é propício à ocorrência de corrupção e ineficiência. Localidades com baixo IDHM possuem maior dependência do Estado no cotidiano das pessoas, tanto no que concerne a prestação dos serviços públicos, quanto a questões de empregabilidade.

Isso gera um ambiente propício à tolerância de pequenas corrupções advindas de práticas clientelistas relativas à busca de vantagens junto ao poder público (Filgueiras, 2009), além do que, perpetua a ineficiência do estado, dado que muitas vezes pessoas são lotadas em funções para as quais não possuem qualificação técnica. Esse fato distancia a população de sua função fiscalizadora, pois cria uma relação de dependência entre massa e elite política (Gay, 1998), necessária para ser instalado um efetivo ambiente de controle que propiciaria à redução dos desperdícios por corrupção e ineficiência. A corrupção deve ser combativa no âmbito das suas pequenas ocorrências, no cotidiano do cidadão comum, para que assim possa se alcançar uma mudança das instituições formais (Filgueiras, 2009).

Destaca-se que sendo os dados de um mesmo período, não foi testada a causalidade. Assim os resultados da Tabela 7 não podem ser associados seja com uma causalidade unidirecional ou reversa entre corrupção, ineficiência e IDHM. As relações que envolvem a corrupção apresentam-se de forma turva por não se saber se é a corrupção que influencia ou é influenciada pelas variáveis como IDH, questão essa, que conforme Mauro (1995), nunca poderá ser totalmente resolvida.

Por fim, como a auditoria do programa é por sorteio, uma questão a ser analisada é quais são outros condicionantes locais que sugeririam uma maior ou menor propensão à ineficiência de gestão e corrupção. Adicionalmente ao contexto clientelista decorrente de fatores sociais, como pobreza e à distribuição de renda, fatores associados a controle poderiam mitigar tais práticas. Entre eles pode-se citar a existência de Controle Interno, atuação de Conselhos Municipais, a proatividade dos Tribunais de Contas e do Legislativo local também deveriam ser considerados. 


\section{CONSIDERAÇÕES FINAIS}

A pesquisa trata da relação entre os desperdícios na contratação pública e o desenvolvimento humano, especificamente na função saúde em municípios brasileiros de 2010 a 2012. Tais desperdícios presentes nos processos licitatórios ocorrem nas formas de corrupção e ineficiência. Um maior nível de corrupção e/ou ineficiência está associado a um menor nível de desenvolvimento humano.

Os resultados são aderentes ao identificado na literatura. Os dados obtidos ratificam estudos de Akçay (2006), Ferraz et al. (2008; 2012), Mauro (1998), Gupta et al. (2000), sendo que tais trabalhos envolvem dimensões do IDH. Ao mostrar a associação negativa entre corrupção e desenvolvimento humano expandem os achados de Akçay (2006) em governos centrais, para governos locais. Ainda, incluem à corrupção as ineficiências gerais na contratação para a função saúde discutida. Adicionalmente, oferece uma reflexão no sentido inverso de causalidade - não testada - normalmente discutido. São apresentados resultados de que ambientes de menor IDH são mais propícios a práticas ilícitas e ineficientes.

Os resultados sugerem dois caminhos a serem investigados e alvo de propostas de reforma institucional. A redução dessas práticas demandaria controle formal e social. O controle formal poderia vir da alteração da regulação de licitações ou da melhor aplicação das mesmas pelos órgãos de controle no monitoramento poderia vir a reduzir níveis de corrupção e ineficiência. Neste caso seria observado com o tempo o aumento da efetividade de tais políticas públicas, uma maior oferta de bens e serviços públicos e uma tendência de melhoria do desenvolvimento humano municipal. A regulação envolveria também ações de transparência pública para monitoramento das licitações. Essa transparência atuaria como um fator indutor para a melhoria da gestão pública. O controle social, subsequentemente com o maior desenvolvimento humano, poderia ser visto no futuro uma menor propensão a um ambiente clientelista, afinal com acesso de todos à saúde, desapareceria a oferta de privilégios relacionados a acessos de serviços de saúde para "os que contam com a proteção de um vereador, ou de um servidor municipal".

Uma contribuição prática dos resultados aqui apresentados, de especial interesse dos órgãos de controle, seria o uso de baixo IDHM como critério a ser incorporado na matriz de risco de auditoria. No sentido de melhor alocar os seus esforços de auditoria, Tribunais de Contas poderiam considerar que baixo IDHM é um ambiente propenso a uso de favorecimento e trocas clientelistas.

Sugere-se novos estudos sobre impactos de corrupção e ineficiência em licitações em outras esferas governamentais (como União e Estados), assim como em outras funções de governo (como educação e assistência social). Contudo, sempre com o destaque que testes de causalidade pediriam avaliações do impacto de longo prazo dos recursos empregados nas políticas públicas específicas.

\section{REFERÊNCIAS}

Abed, G. T., \& Davoodi, H. R. (2000). Corruption, structural reforms, and economic performance in the transition economies.IMF Working Paper No.132. Washington: International Monetary Fund.

Akçay, S. (2006). Corruption and Human Development. Cato Journal, v.26, n.1, p.29-48.

Atlas Brasil (2017). Atlas do Desenvolvimento Humano no Brasil 2013 - Metodologia. Disponível em: <http:// atlasbrasil.org.br>. Acesso em: 28 de agosto de 2017.

Bandiera, O., Prat, A., \& Valletti, T. (2009). Active and passive waste in government spending: evidence from a policy experiment. American Economic Review, 99 (4),1278-1308.

Benfratello, L.; Del Monte, A. \& Pennacchio, L. (2017). Corruption and public debt: a cross-country analysis. Journal Applied Economics Letters, p. 1-5.

CGU. Ministério da Transparência e Controladoria-Geral da União. (2016). Programa de Fiscalização por Sorteios Públicos. Disponível em: <http://www.cgu.gov.br/assuntos/auditoria-e-fiscalizacao/avaliacao-de-programasde-governo/programa-de-fiscalizacao-por-sorteios-publicos>. Acesso em: 20 de março de 2016.

Dias, L. N. S. (2016). Fatores que impactam na corrupção e na ineficiência relacionadas à aplicação de recursos da saúde pública municipal. Tese de doutorado, Universidade Federal de Brasília, Brasília, Distrito Federal, Brasil.

Dias, L. N. S., Matias-Pereira, J., Farias, M. R. S., \& Pamplona, V. M. S. (2013). Fatores associados ao desperdício de recursos da saúde repassados pela união aos municípios auditados pela Controladoria Geral da União. R. Cont. Fin - USP, v. 24, n. 63, p. 206-218. 
Ferraz, C. \& Finan, F. (2008). Exposing corrupt politicians: the effects of Brazil's publicly released audits on electoral outcomes. The Quarterly Journal of Economics, v. 123, n. 2, p. 703-745.

Ferraz, C., \& Finan, F. (2007). Electoral accountability and corruption in local governments: evidence from audit reports. Germany: Institute for the Study of Labor, IZA, Discussion Paper, 2843.

Ferraz, C., Finan, F., \& Moreira, D. B. (2008). Corrupção, má gestão, e desempenho educacional: evidências a partir da fiscalização dos municípios. Anais do Encontro Nacional de Economia, Salvador, BA, Brasil, 36.

Ferraz, C., Finan, F., \& Moreira, D. B. (2012). Corrupting learning: evidence from missing federal education funds in Brazil. Forthcoming.Journal of Public Economics, v.96, p. 712-726.

Filgueiras, F. (2009). A tolerância à corrupção no Brasil: uma antinomia entre normas morais e práticas social. Opinião Pública, Campinas, vol. 15, nº 2, Novembro, p.386-421.

Gay, R. (1998). Rethinking Clientelism: Demands, Discourses and Practices in Contemporary Brazil. European Review of Latin American and Caribbean Studies 65, December, 7-24.

Ghura, D. (1998). Tax Revenue in Sub-Saharam Africa: Effects of Economic Policies and Corruption. IMF Working Paper, n. 98.

Gupta, S., Davoodi, H., \& Alonso-Terme, R. (1998). Does Corruption Affect Income Inequality and Poverty? IMF Working Paper No. 79. Washington: International Monetary Fund.

Gupta, S., Davoodi, H., \& Tiongson E. (2000). Corruption and the Provision of Health Care and Education Services. IMF Working Paper No.116. Washington: International Monetary Fund.

Herrmann, I. (1999). Licitações públicas no Brasil: explorando o conceito de ineficiência por desenho. Revista de Administração, v. 34, n. 2, p. 29-38.

Hessami, Z. (2014). Political corruption, public procurement, and budget composition: Theory and evidence from OECD countries. European Journal of Political Economy. V. 34, p. 372-389.

Jain, A. K. (2001). Corruption: a review. Journal of Economic Surveys, v. 15, n. 1, p. 71-121, 2001.

Kaufmann, D., Kraay, A.,\& Zoido-Lobatón, P. (1999). Governance matters. In: WORLD BANK. Policy research working paper 2196.

Klitgaard, R. (1994). A Corrupção Sob Controle. Rio de Janeiro: Jorge Zahar Editor.

Krueger, A. O. (1974). The political economy of the rent-seeking society. The American Economic Review, v. 64, n. 3, p. 291-303.

Leite, C., \& Weideman, J. (1999). Does Mother Nature Corrupt? Natural Resources, Corruption and Economic Growth. IMF Working Paper No. 85. Washington: International Monetary Fund.

Lopes, M. F. M. (2011). Corrupção: estudo sobre as formas de mensuração, seus determinantes e perspectivas sobre as formas de combate. Tese de doutorado, Fundação Getúlio Vargas, São Paulo, São Paulo, Brasil.

Mauro, P. (1995). Corruption and Growth. Quarterly Journal of Economics. 110 (3), p. 681-712.

Mauro, P. (1996). The Effects of Corruption on Growth, Investment, and Government Expenditure (September 1996). IMF Working Paper, Vol., pp. 1-28. Available at SSRN: https://ssrn.com/abstract=882994

Mauro, P. (1998). Corruption and Composition of Government Expenditure. Journal of Public Economics. V 69, p. 263-279.

Mo, P. H. (2001). Corruption and Economic Growth. Journal of Comparative Economics 29. p. 66-79.

MPF. Ministério Público Federal. (2017). A Lava Jato em números. Disponível em: <http://lavajato.mpf.mp.br/ atuacao-na-1a-instancia/resultados/a-lava-jato-em-numeros>. Acesso em: 19 de agosto de 2017.

Pereira, R. A., \& Campos, F. A. O. (2016). Corrupção e ineficiência no Brasil: Uma análise de equilíbrio geral. Estudos Econômicos (São Paulo), v. 46, n. 2, p. 373-408.

Posner, R. A. (1975). The Social costs of monopoly and regulation. The journal of Political Economy, v. 83, n. 4, p. 807-828. 
Reinikka, R. \& Svensson, J.(2005). Fighting corruption to improve schooling: evidence from a newspaper campaign in Uganda. Journal of the European Economic Association, Papers and Proceedings of the Nineteenth Annual Congress of the European Economic Association,3 (2/3), p. 259-267.

Sant'ana, M. (2008). The evolution of the concept of development: from economic growth to human development. Inter-University Attraction Pole Working Paper.

Scarpin, J. E., \& Slomski, V. (2007, Set./Out.). Estudo dos fatores condicionantes do índice de desenvolvimento humano nos municípios do estado do Paraná: instrumento de controladoria para a tomada de decisões na gestão governamental. Revista de Administração Pública, v. 41, n. 5, p. 909-933.

Shleifer, A., \& Vishny, R. W. (1993). Corruption. The quarterly journal of economics, v 108, n3, p. 599-617.

Silva, C. S., \& Barki, T. V.P. (2012). Compras públicas compartilhadas: a prática das licitações sustentáveis. Revista do Serviço Público. Brasília 63 (2): 157-175, Abr./Jun.

Svensson, J. (2005). Eight Questions about Corruption. Journal of Economic Perspectives. Volume 19, Number 3 , p. $19-42$, Summer.

Tanzi, V. (1998). Corruption around the World: Causes, Consequences, Scope, and Cures." IMF Working Paper No 63. Washington, International Monetary Fund.

Tanzi, V., \& Davoodi, H. (1997). Corruption, Public Investment, and Growth. IMF Working Paper No. 139. Washington: International Monetary Fund.

Tanzi, V., \& Davoodi, H. (2000). Corruption, Growth and Public Finances. IMF Working Paper No. 116. Washington: International Monetary Fund.

TCE-MT. Tribunal de Contas do Estado do Mato Grosso. (2017). CGU estuda corrigir valores de modalidades de licitação e cita iniciativa do TCE-MT. Disponível em: https://www.tce.mt.gov.br/conteudo/show/sid/73/ $\mathrm{cid} / 44864 / \mathrm{t} / \mathrm{CGU}+$ estuda+corrigir+valores + de + modalidades + de + licita $\%$ E7\%E3o+e+cita + iniciativa + do $+\mathrm{T}$ CE-MT. Acesso em: 16 de agosto de 2017.

Transparência Internacional. (2001). Global Corruption Report. Berlin: Transparency International. 1. 2001. Disponível em: <http://www.transparency.org/whatwedo/publication/global_corruption_report_2001>. Acessado em: 23 de novembro de 2016.

Treisman, D. (2000). The Causes of Corruption: A Cross-National Study. Journal of Public Economics, 76: 399457.

Tullock, G. (1967). The welfare costs of tariffs, monopolies, and theft. Western Economic Journal. v. 5, n. 3, p. 224-232.

$\mathrm{Wu}, \mathrm{X}$. (2005). Corporate governance and corruption: a cross-country analysis. Governance: An International Journal of Policy, Administration, and Institutions. v. 18, n. 2, p. 151-170. 